Dicle University Journal of Engineering (DUJE)

web: http://dergipark.gov.tr/dumf

Araştırma Makalesi / Research Article

\title{
Tarihi yapılarda Tahribatsız Yöntemlerle Yapısal Sorunların Tespiti; Diyarbakır Hoca Ahmet (Ayn Minare) Camide Georadar (GPR) Ölçümleri ve Değerlendirilmesi
}

\author{
Detection of structural problems in historical buildings with non-destructive methods; \\ Georadar (GPR) measurements and evaluation in Diyarbakir Hodja Ahmet (Ayn \\ Minaret) mosque
}

\author{
Nursen IŞIK ${ }^{1 *}$, Fatma Meral HALIFEOĞLU ${ }^{2}$ \\ ${ }^{1}$ Dicle Üniversitesi Mimarlık Bölümü, Diyarbakır, isik@dicle.edu.tr. Orcid No: https://orcid.org/0000-0002-6125-1896 \\ ${ }^{2}$ Dicle Üniversitesi Mimarlık Bölümü, Diyarbakır, mhalife@dicle.edu.tr. Orcid No: https://orcid.org/0000-0003-2032-3774
}

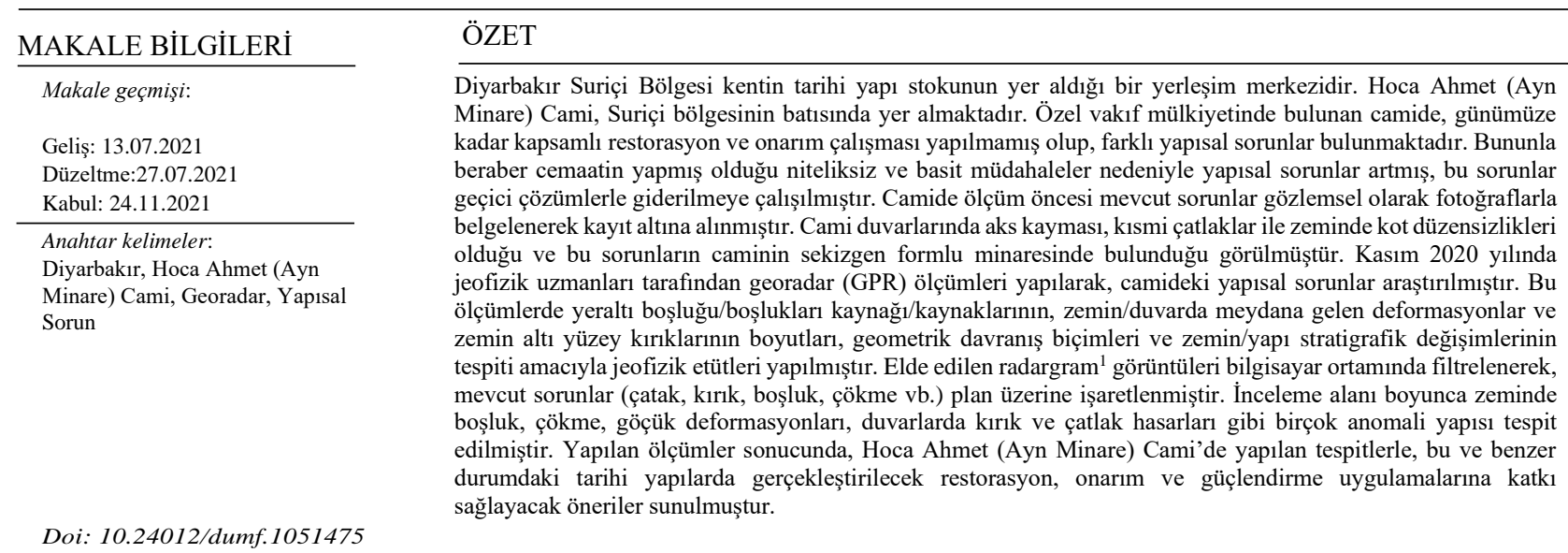

\begin{abstract}
Diyarbakir Suriçi Region is an important settlement center where the historical building stock of the city is located. Hodja Ahmet (Ayn Minaret) mosque is one of the historical mosques located in the south-west of the Suriçi Region. The mosque, which is owned by a private foundation, has not undergone extensive restoration and repair work until today, and it has structural problems. Hodja Ahmet (Ayn Minaret) structural problems have increased due to the unqualified and simple interventions of the congregation in the mosque, and these problems have been tried to be solved with temporary solutions. Before the measurements were made in the mosque, field studies were carried out, existing problems were determined observationally, documented with photographs, and recorded. It has been observed that there are axis shifts, partial cracks and level irregularities on the floor of the mosque walls and that these. problems are also present in the octagonal minaret of the mosque. The radargram images obtained as a result of the measurements were filtered in the computer environment and the existing problems (cracks, fractures, gaps, collapses, etc.) were marked on the plan. During the measurements, the work area was divided into different locations and GPR sections were taken in the form of line / profile at these locations. The penetration depths are set to be different in each location, 4.00 meters on the walls and 20 meters on the ground. Throughout the study area, many anomaly structures such as voids, collapse, dent deformations on the ground, fractures and crack damages on the walls have been detected.

As a result of the measurements made, with the determinations made using Hodja Ahmet (Ayn Minaret) Georadar, suggestions that will contribute to the restoration, repair and strengthening applications to be carried out in this mosque and historical structures in similar conditions were presented.
\end{abstract}

ARTICLE INFO

Article history:

Received: 13.07.2021

Revised: 27.07 .2021

Accepted: 24.11.2021

Keywords:

Diyarbakir, Hodja Ahmet (Ayn

Minaret) Mosque, Georadar,

Structural Problems.
* Sorumlu yazar / Correspondence

Nursen IȘIK

$\triangle$ isik@dicle.edu.tr 


\section{Giriș}

Tarihi yapılar, bulundukları kentlerin sosyal ve kültürel gelişimine katkı sunan mimari miraslarıdır. Kentlerin tarihi dokusu, genellikle kale, cami, kilise, geleneksel ev, han, hamam, köprü vb. birçok anıtsal ve geleneksel yap1 türlerinden oluşmaktadır.

Diyarbakır Suriçi Bölgesi kentin tarihi yapıların yer aldığı sosyal ve kültürel yaşamın aktif olarak sürdürüldüğü canlı bir yerleşim merkezidir.

Suriçi Bölgesinde günümüze ulaşan farklı dönemlerde inşa edilmiş (7yy-16 yy) birçok cami bulunmaktadır. Bölgenin kuzeybatısında beşinci haremi şerif olarak kabul edilen Ulu Cami ile Nebi Cami, İskender Paşa Cami, Melik Ahmet Paşa Cami, kuzeyde Hz. Süleyman Cami, kuzeydoğusunda, Nasuh Paşa Cami, Fatih Paşa (Kurşunlu Cami), güneyde Şeyh Mutahhar Cami ve Dört ayaklı Minare, Hüsrev Paşa Cami, güneybatıda Behram Paşa Cami, Lala Kasım Paşa (Lale Bey) Cami, Hoca Ahmet (Ayn Minare) Cami bunu oluşturan en önemli yapılardandır. Birçoğu ibadete açı camilerin bazılarında zaman içinde oluşan yapısal sorunları kısmi restorasyon çalışmalarıyla giderilmiştir. Ancak, kamu mülkiyetinde olmayan camilerde ise bu sorunlar cemaat ya da hayırseverler tarafindan basit müdahalelere ve uzman görüşüne dayanmayan çözümlerle giderilmeye çalışılmıştır.

Hoca Ahmet (Ayn Minare) Cami özel vakıf (Hoca Ahmed Cami-i Şerifi Vakfi $)^{1}$ mülkiyetinde olup, yapısal sorunları ile varlığını sürdürmeye çalışmaktadır.

Tarihi yapılardaki yapısal sorunların belirlenmesi amaciyla son y1llarda tahribatsiz ölçüm yöntemleri yaygın olarak kullanılmaya başlanmıştır. Georadar (GPR) yöntemi, yapıya zarar vermeyen, zemin ve duvarlarda diștan görünmeyen hasarların tespitinde kullanılan tahribatsiz uygulanan jeofizik yöntemlerinden biridir.
Özellikle tarihi yapilarda tahribatsı yöntemlerinden biri olan georadar uygulaması gerek zeminde ve gerekse tüm yapı özelinde hasarların belirlenmesi amaciyla kullanılmaktadır. Yapıların duvar ve zeminlerindeki hasar ve bozulmalar tahribatsız görüntüleme teknikleri kullanılarak tespit edilebilmektedir. Yüksek çözünürlüklü ekipman, veri toplama, işleme ve modelleme tekniklerinin geliştirilmesi, jeofizik yöntemlerin uygulama kapsamını artırmıştır [2].

$\mathrm{Bu}$ çalışmada, Hoca Ahmet (Ayn Minare) Camide mevcut yapısal sorunlar görsel analizlerle incelenip, aletsel ölçümlerle desteklenmiştir. Diştan gözlemlenemeyen (çatlak, kırık, çökme, vb.) hasarların georadar (GPR) ölçümleriyle zemin ve duvar taramaları yapılmıştır. Cami çevresinde birçok yapının bulunmas1 nedeniyle georadar (GPR) taramalarında farklı profil boyutları seçilerek ölçümler yapılmıştır.

Uzman jeofizik mühendisleri tarafindan yapılan ölçümler ve taramalar sonucunda radargramlar çıkartılarak, yapısal sorunların neden olduğu deformasyon bölgeleri kayıt altına alınmıştır

Georadar (GPR) taramalarının yapıldığı Hoca Ahmet (Ayn Minare) Camide duvarlarda aks kayması, çatlak, kırık, zeminde çökme, zemin suyuna bağlı boşalmalar belirlenmiştir.

Georadar (GPR) ölçümleri sonucu tespit edilen sorunlara yönelik öneriler sunularak, çalışma tamamlanmıştır.

\section{Hoca Ahmet (Ayn Minare) Cami'nin Suriçi Bölgesindeki konumu ve mimari özellikleri}
Hoca Ahmet (Ayn Minare) Cami, Suriçi Bölgesinin güneybatısında, Ali Paşa Mahallesinde yer almaktadır. Yapının kuzey yönünde Binici Sokak ile doğu yönünde Ilgaz Sokaktan sağlanan iki girişi bulunmaktadır (Şekil 1, Şekil 2).

\footnotetext{
1 Vakıflar Genel Müdürlüğü Arşivi, Akmaz, 2019
} 

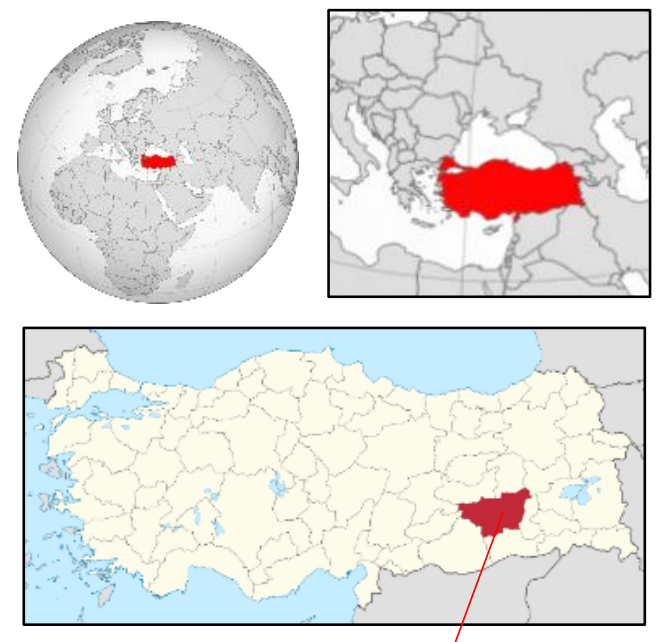

Şekil 1. Türkiye ve Diyarbakır'ın Konumları [URL 1, URL 2]

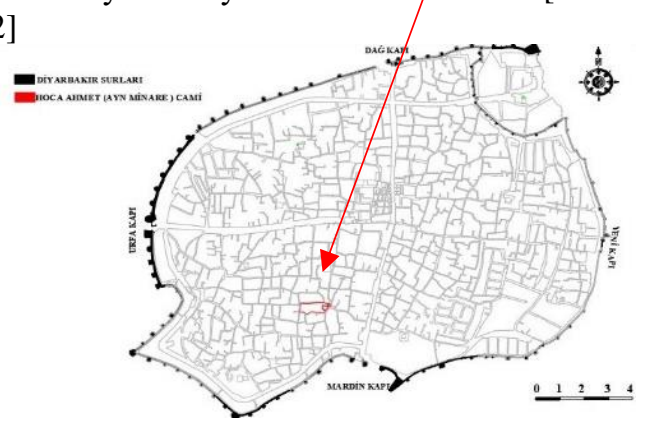

Şekil 2. Hoca Ahmet Paşa Caminin Surçi Bölgesindeki konumu [3]

Kaynaklara göre 1498 yılında inşa edilen yapı harim, son cemaat yeri, avluda betonarme sekizgen şadırvan, gasilhane, hela, depo ve gövdesi sekizgen formlu minareden oluşmaktadır [4] [5] (Şekil 3).
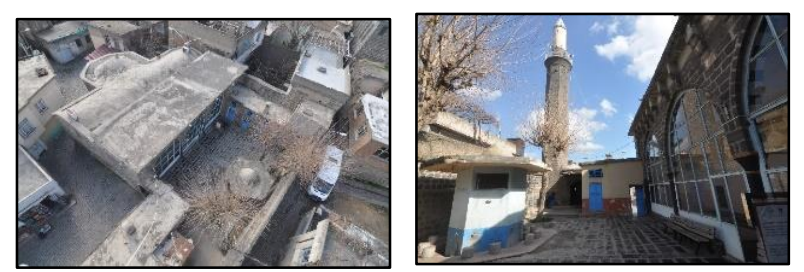

Şekil 3. Hoca Ahmet Paşa Cami minareden görünümü ve kuzey cephesi (2021)

Caminin avlusuna Ilgaz sokaktan girilmektedir. Yığma yapım tekniğiyle inşa edilen cami ters $\mathrm{T}$ plan düzenindedir. Camide ana yapım malzemesi olarak bazalt taş kullanılmıştır. Caminin kuzey doğusunda gasilhane, hela, depo ve minare bulunmaktadır.

Avluya bakan kuzey cephesinde bulunan üç adet sivri kemerli sütunlarla taşıtılan son cemaat yeri, metal doğramalarla kapatılmıştır. Caminin harim doğu batı doğrultusunda beşik tonozla geçilmiştir (Şekil 4).
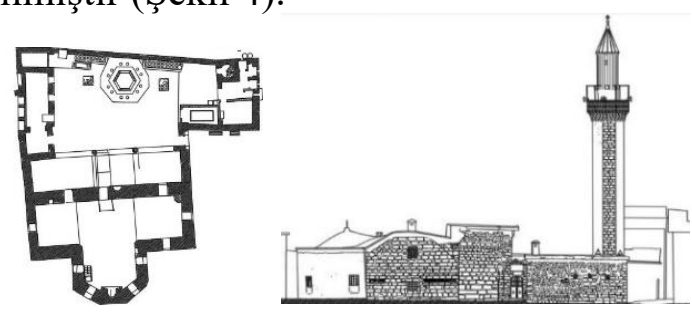

Şekil 4. Hoca Ahmet (Ayn Minare) Cami Plan ve Doğu Cephesi [6]

Daha önce tonoz örtülü olduğu kaynaklarda ${ }^{2}$ belirtilen son cemaat yerinde, üst örtü betonarme olarak değiştirilmiştir. Son cemaat yerindeki kemerlerin bir ucu duvara sabitlenmiş gergi çubukları bulunmaktadır. Son cemaat yerine avlu kotundan düz girilmekte olup, girişin doğu ve batı yönündeki zemini yaklaşık $30 \mathrm{~cm}$ 'lik zemini şap döşeme ile yükseltilmiştir. Son cemaat yerinden alçak bir kapıyla harime girilmektedir.

Harim, üç bölüme ayrılmakta olup, girişin karşısında yarım sekizgen formlu mihrap yer almaktadır. Harimin doğu ve batı zemin döşemesi yükseltilmiş, üst örtüsünde beşik ve çapraz tonoz birleştirilmiştir.

Harimin doğusundaki bölüm, sivri kemer ve beşik tonozla geçilmiştir. Bu bölümde yuvarlak, batı bölümünde ise sivri kemerler içerisinde dikdörtgen pencereler yer almaktadır. Mihrabın köşe duvarlarında düz lentolu dörtgen formlu pencereler bulunmaktadır. Pencerelerin altlarında nişler vardır.

Harim duvarlarının tümü sıva ile kapatılmıştır. Harim döşemesinin yükseltilmesi ile pencereler

\footnotetext{
2 E. Akmaz, Bilgiç. "Diyarbakır Hoca Ahmed (Ayni Minare) Camii Restorasyon Önerisi" Dicle Üniversitesi

Fen Bilimleri Enstitüsü, Yayımlanmamış Yüksek Lisans Tezi. Diyarbakır. 2019.
} 
zeminden yaklaşık $15 \mathrm{~cm}$ yükseklikte kalmıştır. Mihrabın bulunduğu bölüm, sivri kemerle üst örtüsü, çapraz tonoz ve beşik tonozla geçilmiştir. Harim zemininde kot düzensizlikleri bulunmakta olup, döşeme halı ile kaplanmıştır (Şekil 5).
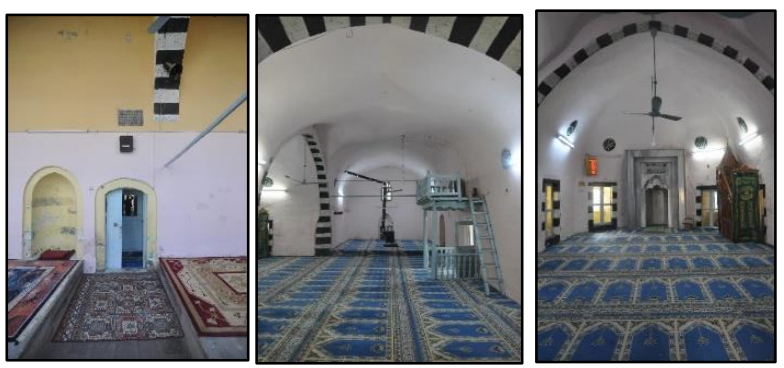

Şekil 5. Hoca Ahmet (Ayn Minare) Cami harimin girişi ve iç alanlar (2021)

\section{Hoca Ahmet (Ayn Minare) camide tespit edilen yapısal sorunlar}

Hoca Ahmet (Ayn Minare) Cami Suriçi Bölgesinin güney batı diliminde yer almakta olup, günümüzde aktif olarak kullanılmaktadır. Hoca Ahmed Cami-i Şerifi Vakfı mülkiyetine ait camide günümüze kadar kapsamlı onarım ve restorasyon yapılmamıştır.

Yı̆̆ma yapım tekniğiyle inşa edilmiş yapıya zaman içinde basit ve niteliksiz müdahaleler yapılarak, kısmi olarak yapım sistemi değiştirilmiştir. Beşik tonozlu ve çapraz tonozla birleşimi sağlanan üst örtünün tümü beton malzemeyle kapatılarak yapıda düzensiz yük aktarımları oluşmuştur. Bazalt taş malzemeyle yapılmış bingi taşlarının bulunduğu son cemaat yerinin üst örtüsü, harim üst örtüsünün devamı olarak betonarme malzeme ile değiştirilmiştir (Şekil 6).
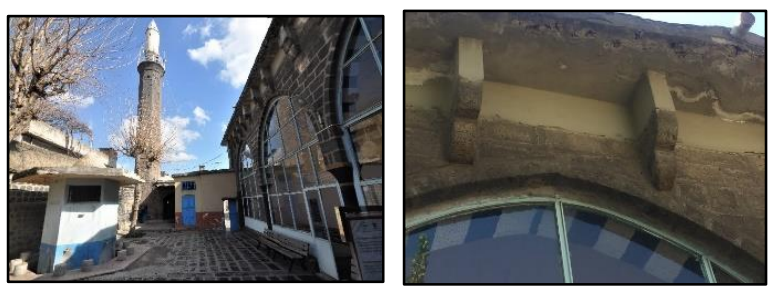

Şekil 6. Hoca Ahmet (Ayn Minare) Camide son cemaat yerinde silme üstlerine eklenen beton döşeme

Son cemaat yerinin üst örtüsünün beton malzeme ile değiştirilmesi ile cephe duvarlarında kısmen ayrışma ve harç kayıpları oluşmuştur. Ayrıca yalıtımın eksik ve yetersiz kaldığı üst örtüden kaynaklanan nem problemleri bulunmaktadır. $\mathrm{Bu}$ sorun harim bölümünün tümünde devam etmektedir. Siva ve boyalı harim ve son cemaat yeri duvarlarında nemlenmeye bağlı kabarmalar mevcuttur.

Harimin doğu ve batı bölümlerindeki zeminlerde, oturmalara bağlı oluştuğu düşünülen ve sonradan yükseltilmiş döşemede kısmi kot düzensizlikleri bulunmaktadır.

Harimin güneyindeki iç ve dış duvarlarında aks kayması mevcuttur. Aks kaymasının bulunduğu duvarların bulunduğu zeminde, yer yer çökmeler olduğu görülmüştür. Ayrıca sokak cephe duvarlarında, harç kaybına bağlı ayrışmalar mevcut olup, daha çok pencere kenarlarında yoğunlaşmıştır (Şekil 7).
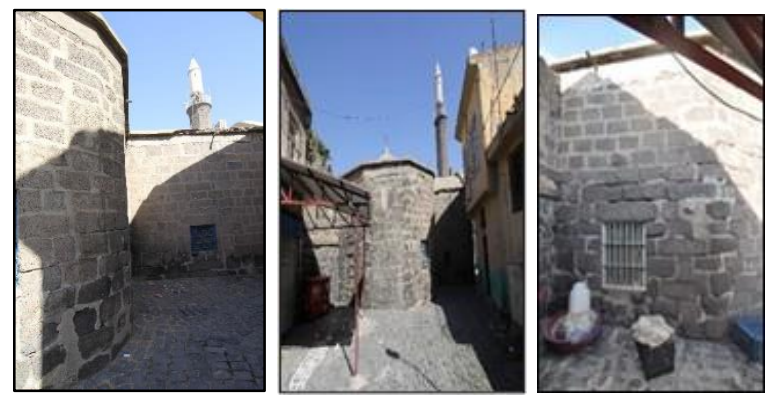

Şekil 7. Hoca Ahmet Cami güney cephe duvarında, aks kayması, harç kaybı ve ayrışma hasarları

Caminin kuzeydoğusunda bulunan hela, depo, bölümleri sonradan tuğla ve betonarme malzeme kullanılarak tümüyle değiştirilmiştir. $\mathrm{Bu}$ bölümlerde, 1slak hacimlerden kaynaklanan yalıtım ve nem problemleri bulunmaktadır.

Caminin kuzeydoğusunda bulunan, gövdesi bazalt taştan sekizgen formda yapılmış minarenin petek bölümünde harç kayıplarına bağlı ayrışmalar mevcuttur. Minarenin, tuğla malzeme ile tamamlanan külah bölümünde sıva kayıpları ve nem problemleri oluşmuştur. Ayrıca minarenin iç merdiven basamaklarında kırık ve çatlak şeklinde malzeme kayıpları olduğu görülmüştür (Şekil 8) 

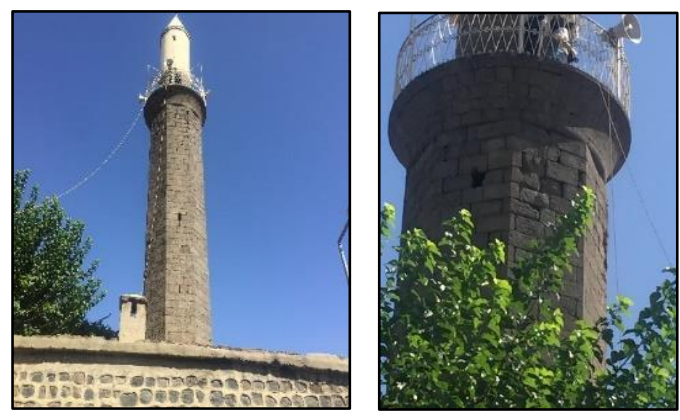

Şekil 8.Hoca Ahmet Cami minaresinde harç kaybı ve ayrışmaya bağlı oluşan yapısal sorunlar

\section{Hoca Ahmet Camide yapılan georadar (GPR) ölçümleri ve değerlendirmeleri}

Hoca Ahmet (Ayn Minare) Camide yapısal sorunların tespiti için zemin ve duvarlarda georadar (GPR) taramaları yapılmıştır. Yapılan duvar ve zeminlerdeki georadar (GPR) taramalarında Python-3 GPR cihazı kullanılmıştır. Python-3 GPR, özellikle derin anketler (olumlu zeminde 65 metreye kadar) için kullanılan tek bir operatör tarafından taşınan bir taşınabilir dijital yeraltı radarıdır.

Georadar (GPR) ölçüm çalışmalarında veri işlem basamakları izlenerek, bu işlemler için Reflex W [6] (programı kullanılmıştır (Şekil 9)

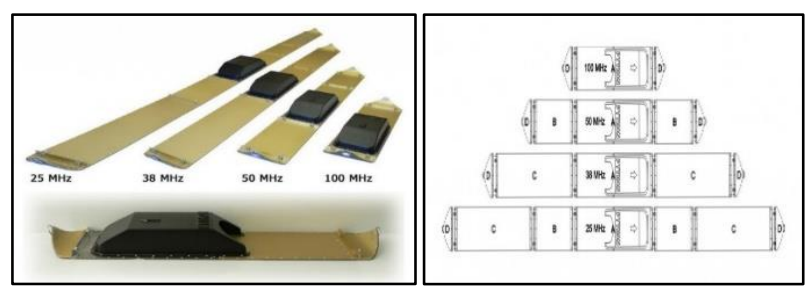

Şekil 9.Zond Ptyhon 3 GPR Mhz merkez anteni ve 1.6 Ghz ve diğer açık antenlerinin şematik gösterimi [URL 3] [URL 4]

Hoca Ahmet (Ayn Minare) Camide yapılan taramalarda, zemin yapısı, istif değişimleri, jeolojik yapı, yer altındaki boşluk durumları, zemin/duvarlarda muhtemel kırık, çatlakların boyutları ve geometrik davranış biçimleri belirlenmeye çalışılmıştır.

Camide yapılan alan çalışmasında, görsel araştırma ve aletsel tespitler yapılmıştır. Jeofizik uzmanları tarafindan yapılan georadar taramalarında, jeolojik formasyonların durumu, değişimi, çevre kayaçların özellikleri ile elektromanyetik geçirgenliklerine göre sinıflandırmalar göz önünde bulundurulmuştur.

Georadar (GPR) taramalarının yapıldığı çalışma alanı, farklı lokasyonlara ayrılarak, bu lokasyonlarda hat/profil şeklinde GPR kesitleri alınmıştır. Penetrasyon ${ }^{3}$ derinlikleri her lokasyonda farklı olmak üzere en dar duvarda 2.00 metre, geniş duvarlarda 4.00 metre, zeminde en siğ 10 metre en derin 20 metre olacak şekilde ayarlanmıştır. Çalışma boyunca $100 \mathrm{Mhz}$ ve $1.8 \mathrm{Ghz}$ anten kullanılmıştır.

Hoca Ahmet (Ayn Minare) Camide, georadar (GPR) taramalar1 harim ve son cemaat yerinin cephe duvarları ile zemininde yapılmıştır. Ayrıca avlu, minare ve sokak cephesindeki zemin kot değişim nedenlerinin belirlendiği taramalar ile zeminin mevcut durumları ve yapisal sorunlar tespit edilmiştir.

Georadar ölçümlerinin yapıldığı bu çalışmada cami zemin ve duvarlarındaki muhtemel deformasyonların yerleri, boyutlarının belirlenmesi amaçlanmıştır. Alan çalışmasında görsel olarak tespit edilen hasarlar, aletsel taramalar ile hasar düzeyleri ve konumları belirlenmiştir.

\section{Hoca Ahmet (Ayn Minare) Cami zeminde yapılan georadar (GPR) taramaları}

Hoca Ahmet (Ayn Minare) caminin harim, son cemaat yeri, avlu ve 1slak hacimler ve minare zemininde ayrı taramalar yapılarak, zeminin mevcut durumları tespit edilmiştir.

\section{Georadar (GPR) 1 zemin taramalart}

Hoca Ahmet (Ayn Minare) Cami harim bölümünün, doğu yönündeki zeminde 80.00 metre profil boyu ve 15.00 metre penetrasyon derinliği seçilerek taramalar yapılmıştır.

Elde edilen radargram kesitlerinde zeminin yaklaşık 2.50 metre kadar orta gevşek birim, 2.510.00 metreler arası orta sert formasyon olduğu

\footnotetext{
${ }^{3}$ Penetrasyon derinliği, elektromanyetik radyasyonun nüfuz edebileceği bir malzemedeki derinliktir [URL 5]
} 
iki farklı seviye tespit edilmiştir. Ayrıca 7.50 metreden sonra zeminde birtakım örselenmelerin olduğu, bu örselenmelerin zamanla gevşeyen zemin ve suya maruz kalan alanlardan kaynaklandığı yapılan hız analizleri ${ }^{4}$ sonucunda belirlenmiştir (Şekil 10, Şekil 11).
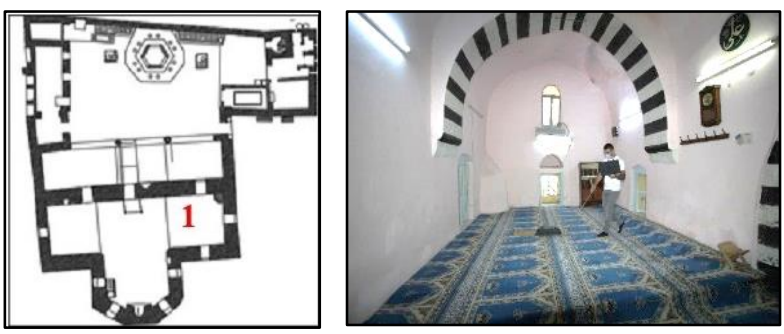

Şekil 10. Hoca Ahmet (Ayn Minare) Cami harimin doğu yönündeki zeminde yapılan georadar (GPR) taramaları ve konumları

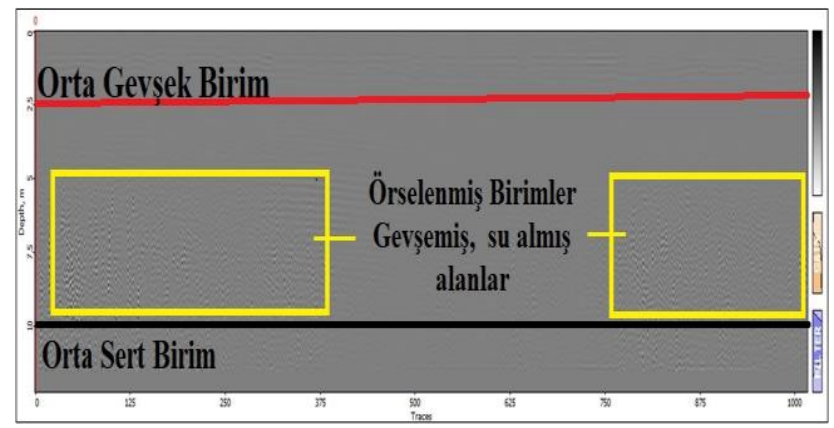

Şekil 11. Hoca Ahmet (Ayn Minare) Cami harim zeminindeki GPR 1 taramaları sonucu elde edilen radargram kesiti

\section{Georadar (GPR) 2 zemin taramalart}

Harimin orta bölümündeki zeminde 40.00 metre profil boyu ve 20.00 metre penetrasyon derinliği seçilen georadar (GPR) taramaları yapılmıştır. Elde edilen radargram kesitlerinde yaklaşık 3,00 metreye kadar orta gevşek formasyon, 3.00-7.50 metreler orta sert formasyon olduğu iki farklı seviye tespit edilmiştir. Yapılan taramalar sonucunda profil boyunca istif değişimleri dışında anomali yapısına rastlanmamıştır (Şekil 12, Şekil 13).

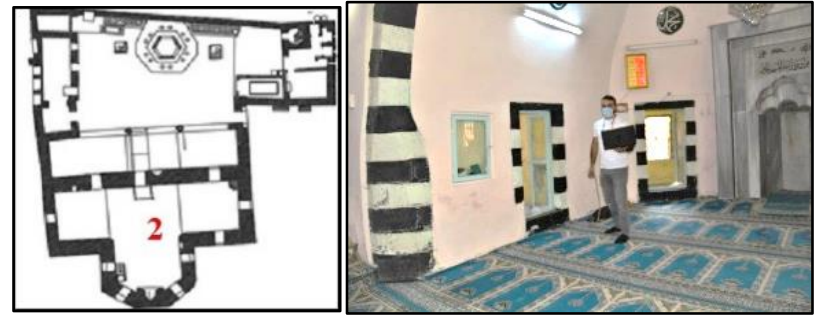

Şekil 12. Hoca Ahmet (Ayn Minare) Cami harim orta bölümünün zemindeki georadar (GPR) 2 taramaları ve konumlar1

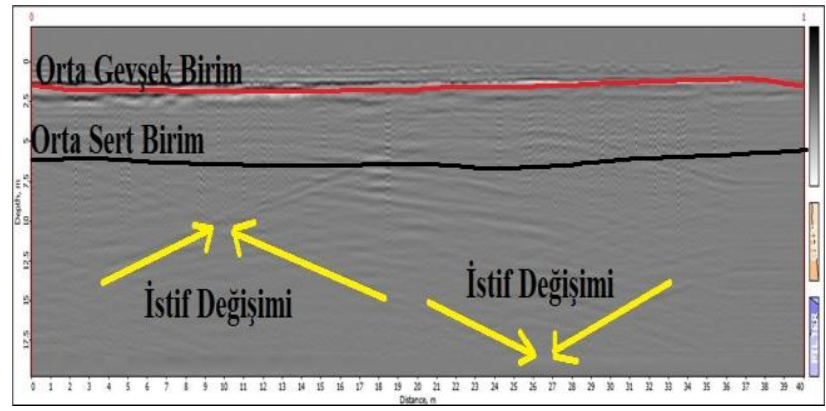

Şekil 13. Hoca Ahmet (Ayn Minare) Cami harim zeminindeki GPR 2 taramalar sonucu elde edilen radargram kesiti

\section{Georadar (GPR) 3 zemin taramalart}

Harimin batı yönündeki zeminde yapılan georadar (GPR) taramalarında, 100 metre profil boyu, 15.00 metre penetrasyon derinliği seçilmiştir. Zeminin yaklaşı 3.00 metre derinliğinde orta gevşek formasyon, 3.00-7.00 metre aralığında orta sert formasyon olduğu görülmüştür.

Zeminin yaklaşık 2.00-7.00 metre derinliğinde 11.25-12.50 traces aralığında, boşluk anomali yapısı tespit edilmiştir.

Taramalarda tespit edilen boşluk yapısı, yaklaşık $0.13 \mathrm{~ns} / \mathrm{cm}$ değerindeki hiz analizleriyle doğrulanmıştır. Stratigrafik değişim bölgeleri radargram kesitlerinde işaretlenmiştir. (Şekil 14, Şekil 15).

\footnotetext{
${ }^{4}$ Hız analizi: Derinliğin fonksiyonu olarak hızı kullanarak yer radarı verisinden hız analizi yapmak veri işlem tespitlerinden biridir [8]
} 

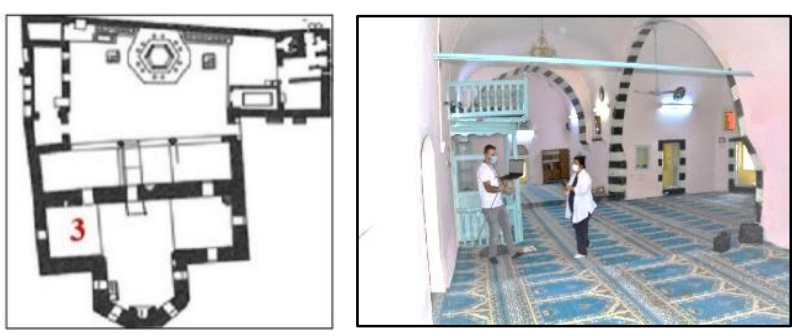

Şekil 14.Hoca Ahmet (Ayn Minare) Cami harimin batı bölümü zemindeki georadar (GPR) 3 taramaları ve konumları

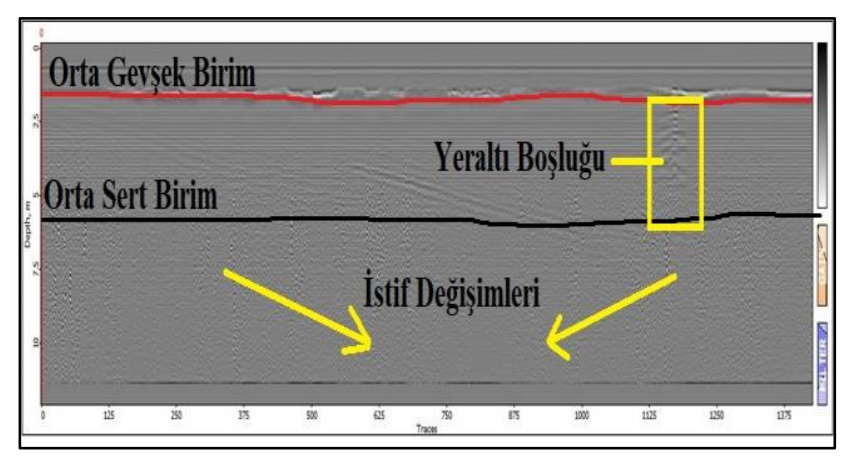

Şekil 15. Hoca Ahmet (Ayn Minare) Cami harim zeminindeki GPR 3 tarama sonucu elde edilen radargram kesiti

\section{Georadar (GPR) 4 ve (GPR) 5 zemin taramalart}

Harim ve son cemaat yeri zemininde yapılan georadar (GPR) taramalarında, 100.00 metre profil boyu ve 20.00 metre penetrasyon derinliği seçilmiştir.

Zeminin yaklaşık 3,00 metre derinliğinde orta gevşek formasyon, 3.00-7.00 metre aralığında orta sert formasyon olduğu düşünülen katmanlar bulunmaktadır. İstif değişimlerinin belirlendiği zeminde suya bağlı deformasyonların oluştuğu bölgeler tespit edilmiştir (Şekil 16, Şekil 17).
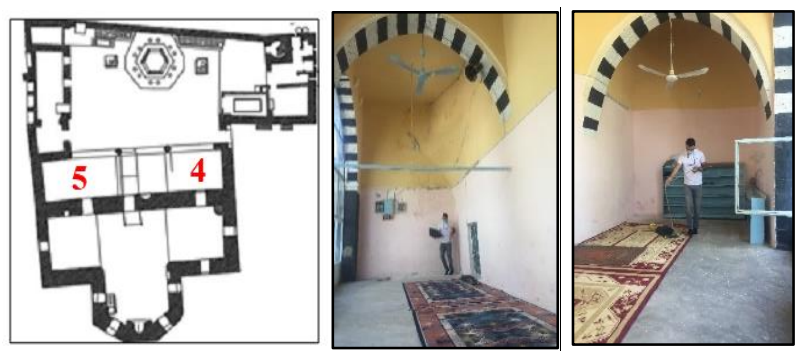

Şekil 16. Hoca Ahmet (Ayn Minare) cami son cemaat yeri doğu bölümü zemini GPR 4, GPR 5 taramaları ve konumlar1

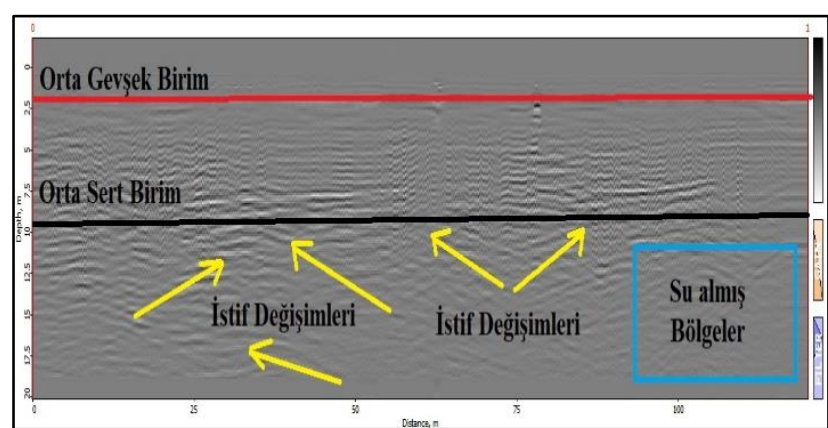

GPR 4

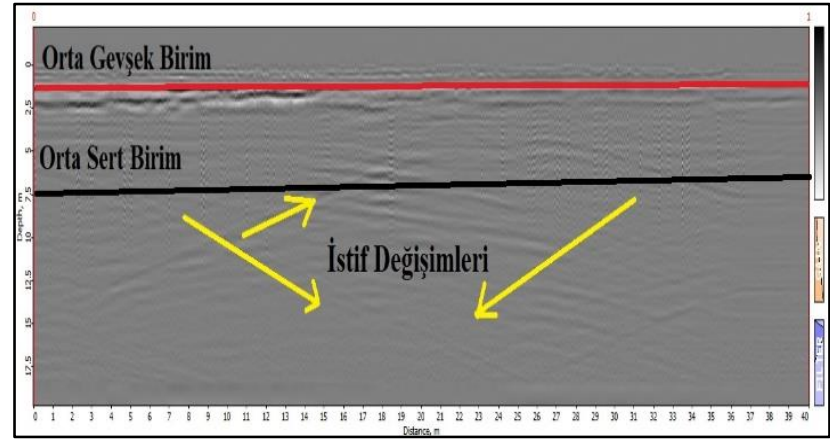

GPR 5

Şekil 17. Hoca Ahmet (Ayn Minare) cami son cemaat yeri doğu bölümü zemini GPR 4- GPR 5 tarama sonucu elde edilen radargram kesiti

\section{Georadar (GPR) 6- (GPR) 7- (GPR) 8 zemin taramaları}

Avlu zemini, üç alana bölünerek ölçümler yapılmış, profil boyu 80 metre, penetrasyon derinliği 20 metre olarak seçilmiştir. Avlunun zemininde, 3.00 metreye kadar orta gevşek formasyon, 3.00 metre-7.00 metre aralığında orta sert formasyon belirlenmiştir.

Georadar taramaları sonucunda, elde edilen radargram kesitlerinde GPR 6 olarak belirlenen avlunun doğu bölümünde, saçılmalara bağlı dielektrik yapıların oluştuğu görülmüştür.

GPR 7 taramalarının yapıldığı avlu zemininde yaklaşık 7.50-14.00 metre derinlikte, su etkisiyle çökmelerin oluştuğu tespit edilmiştir.

Cami avlusunda GPR 8 taramalarında kesit boyunca hâkim ve 12.50 metre derinlikte bir adet su tablasinın ${ }^{5}$ olduğu, bu tablanın su kanalı özelliği taşıdığı yapılan hız analizleri ile

${ }^{5} \mathrm{Su}$ tablası: Yer altı suyu seviyesi veya yer altı su tablası iki zone arasında atmosfer basıncı ile su basıncının eşit olduğu yüzeydir [URL 6] 
doğrulanmıştır. Hız analizleri 3,3 (cm/ns) olarak ölçülmüştür (Şekil 18, Şekil 19).
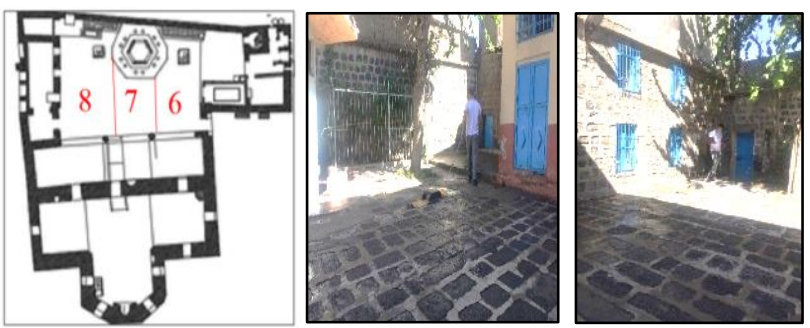

Şekil 18. Hoca Ahmet (Ayn Minare) cami avlu zemininde yapılan GPR 6- GPR 7- GPR 8 taramaları ve konumları
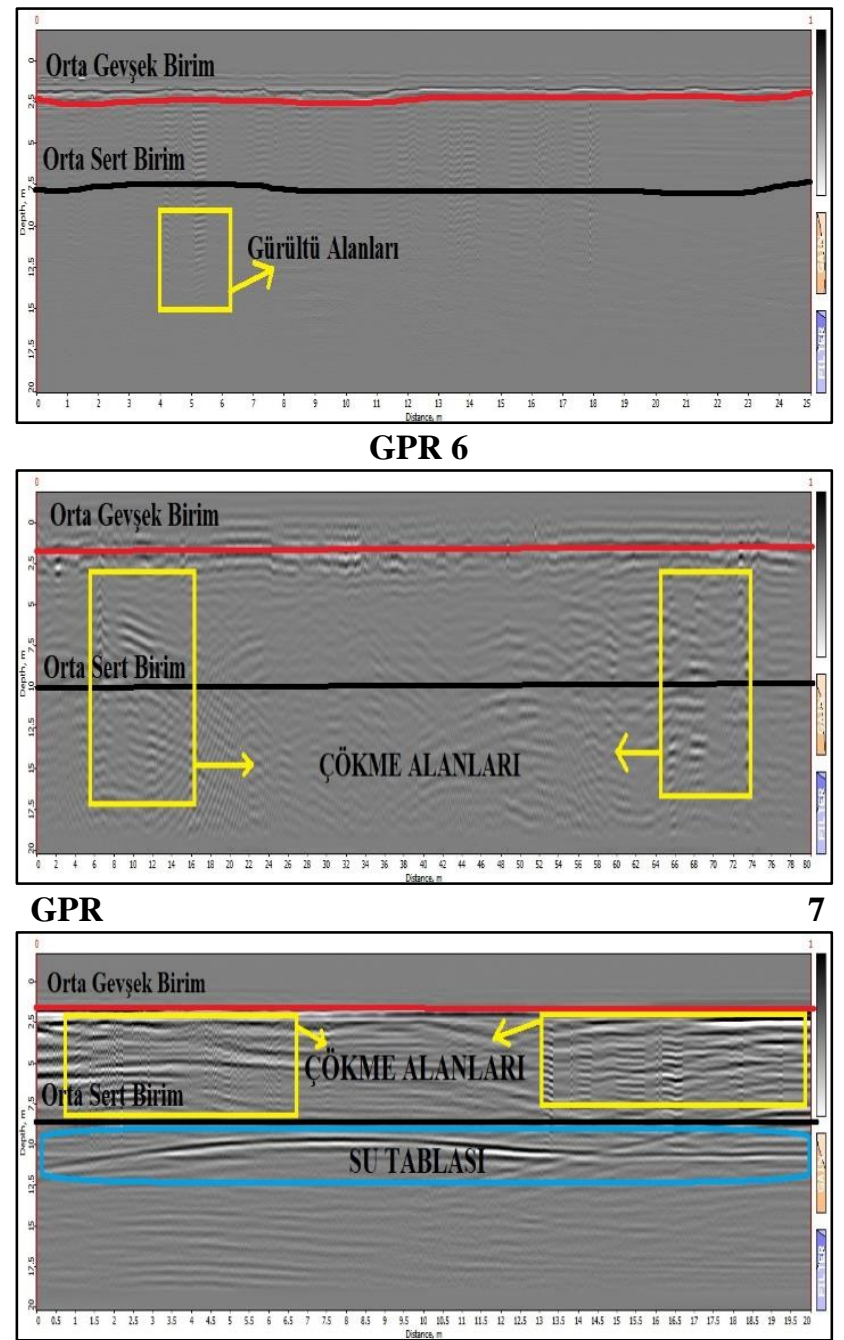

GPR 8

Şekil 19. Hoca Ahmet (Ayn Minare) cami avlu zemininde yapılan GPR 6- GPR 7- GPR 8 tarama sonucu elde edilen radargram kesitleri

\section{Georadar (GPR) 9 zemin taramalart}

Caminin kuzeydoğusundaki, WC ve minarenin bulunduğu alanda yapılan georadar (GPR) taramalarında 25 metre profil boyu, 20 metre penetrasyon derinliği seçilmiştir.
Islak hacimler (WC, depo vb.) ve minare çevresinde, caminin tümünde tespit edilen 3.00 metreye kadar orta gevşek formasyon, 3.00-7.00 metrede orta sert formasyon olmak üzere iki ayrı tabaka olduğu tespit edilmiştir. 12.5-17.5 metreler arasında istif değişimleri olduğu belirlenmiştir (Şekil 20, Şekil 21).
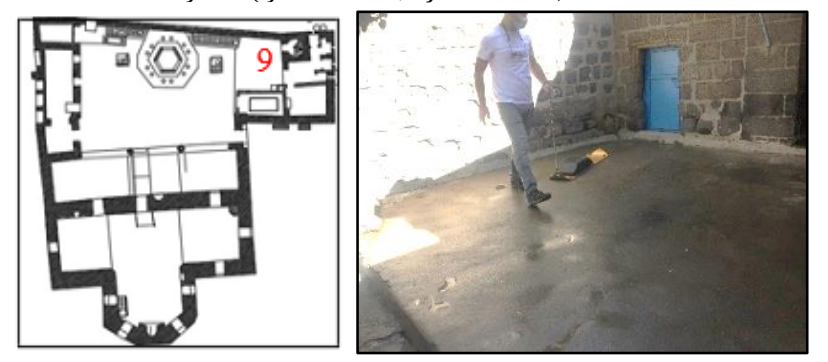

Şekil 20. Hoca Ahmet (Ayn Minare) Cami gasilhane ve minare zemininde yapılan GPR 9 taramaları ve konumları

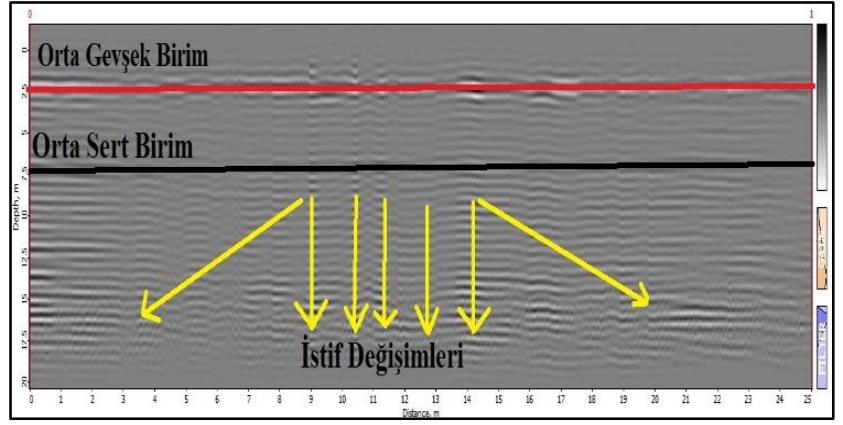

Şekil 21. Hoca Ahmet (Ayn Minare) cami avlu zemininde yapılan GPR 9 tarama sonucu elde edilen radargram kesitleri

\section{Georadar (GPR) 10 zemin taramalart}

Harim bölümünün güney ve güneydoğu duvarında görsel olarak tespit edilen aks kaymasının nedeninin belirlenmesi amaciyla, Ilgaz Sokak zemininde georadar (GPR) taramaları yapılmıştır. Yapılan georadar (GPR) taramalarinda 30 metre profil boyu 20 metre penetrasyon derinliği seçilmiştir.

Taramalar sonucunda elde edilen radargram kesitlerinde, zeminin yaklaşık 14-17 metre aralığında boşluk anomalisi tespit edilmiştir. $\mathrm{Bu}$ yapının boşluk olduğu yapılan hız analizleri ile yaklaşık olarak $0.13 \mathrm{~ns} / \mathrm{cm}$ değer ile doğrulanmıştır.

Cami harim duvarının, iç ve diş bölümlerinde görülen aks kaymasının, zemin taramalarında tespit edilen boşluğa bağlı olduğu görülmüştür. 
Ayrıca bu bölümde, zeminde belirlenen su sızıntılarına bağlı çökmeler olduğu düşünülmektedir (Şekil 22, Şekil 23).
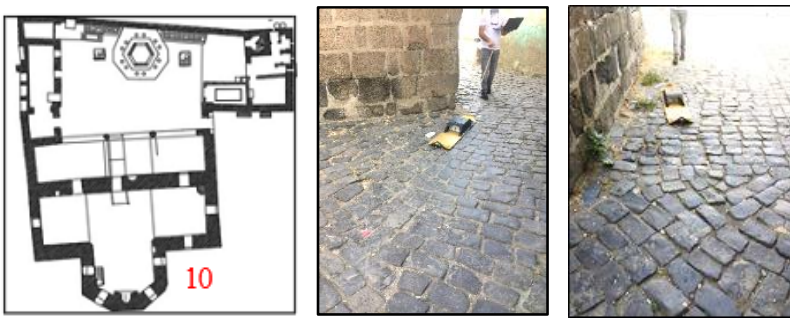

Şekil 22. Hoca Ahmet (Ayn Minare) Cami aks kayması bulunan harim güney duvarının bulunduğu sokak zemininde yapılan GPR 10 taramaları ve konumları

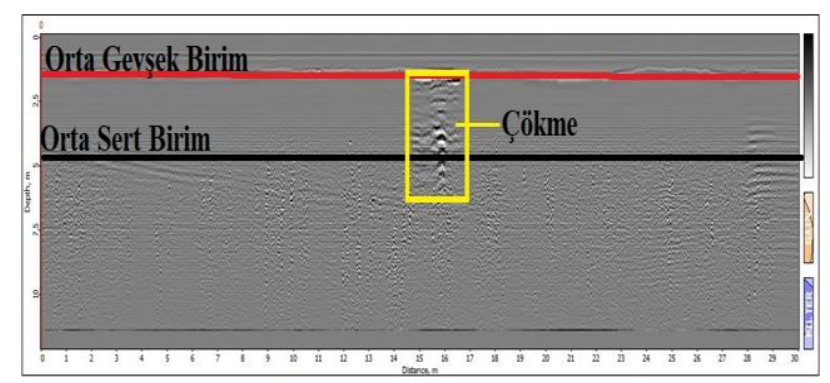

Şekil 23. Hoca Ahmet (Ayn Minare) Cami aks kayması bulunan harim güney duvarının zemininde yapılan GPR 10 tarama sonucu elde edilen radargram kesitleri

\section{Georadar (GPR) 1 duvar taramalart ve konumları}

Harimin doğu duvarında yapılan georadar (GPR) taramalarında 26.00 metre profil boyu ve 4.50 metre penetrasyon derinliği seçilmiştir. Profilde elde edilen radargram kesitlerinde, duvarda kırık deformasyonları tespit edilmiştir.

Yaklaşık olarak 0.50-4.00 metre derinlikte ve 50.00 ile 300 traces aralığında kırıklı ve çatlaklı anomali yapılarının olduğu yapılan hız analizleri ile doğrulanmıştır (Hız analizleri data prosesleri anında bakılabilen parametreler olup, radargram kesitleri üzerinde görsel formatta gösterilemezler) [9] (Şekil 24, Şekil 25).
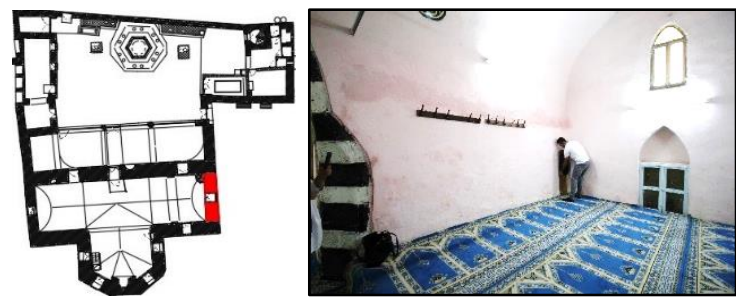

Şekil 24.Hoca Ahmet (Ayn Minare) Cami aks kayması bulunan harim doğu duvarında yapılan GPR 1 taramaları ve konumları

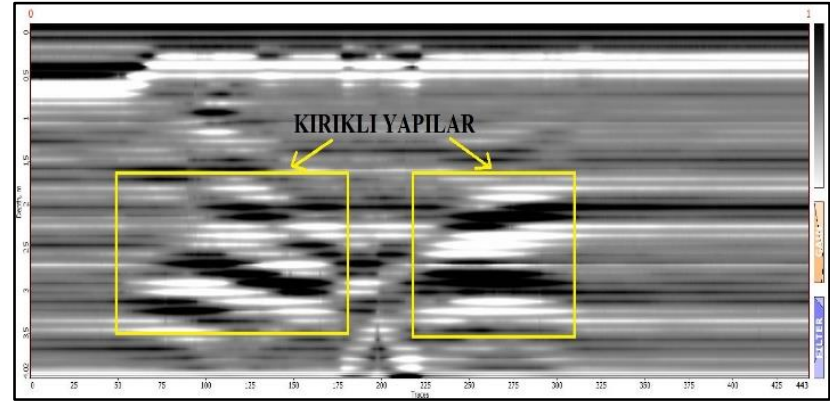

Şekil 25.Hoca Ahmet (Ayn Minare) Cami aks kayması bulunan harim doğu duvarında yapılan GPR1 taramaları sonucu elde edilen radargram kesitleri

\section{Georadar (GPR) 2 duvar taramalart ve konumlart}

Harim güney duvarının doğu yönünde yapılan georadar (GPR) taramalarında 15.00 metre profil boyu ve 4.00 metre penetrasyon derinliği seçilmiştir. Profilde elde edilen radargram kesitinde duvarda çatlakların bulunduğu görülmüştür. Özellikle 1.50-2.00, derinlikte ve 3.50-4.00 metreler arasında kırıkların olduğu, bu kırıkların yapıda kullanılan bazalt taş içindeki muhtemel gaz boşlukları ile zeminde tespit edilen boşlukların (çökme) etkisiyle oluştuğu düşünülmektedir (Şekil 26, Şekil 27).
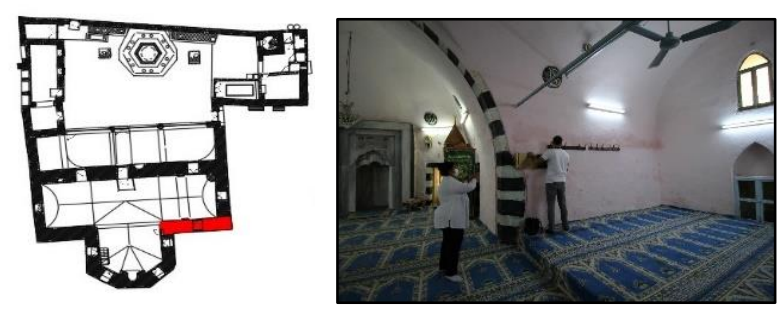

Şekil 26. Hoca Ahmet (Ayn Minare) Cami aks kayması bulunan harim güney duvarının doğu yönündeki duvarında yapılan GPR 2 taramaları ve konumları

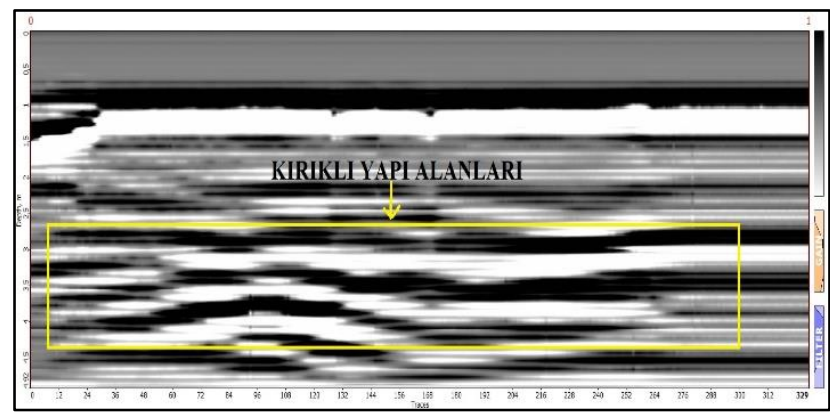

Şekil 27.Hoca Ahmet (Ayn Minare) Cami aks kayması bulunan harim güney duvarının doğu yönünde yapılan GPR 2 taramaları sonucu elde edilen radargram kesitleri 


\section{Georadar (GPR) 3 duvar taramalart ve konumlart}

Yarım sekizgen planlı mihrabın yer aldığı güney duvarında yapılan georadar (GPR) taramalarında 22.00 metre profil boyu ve 4.00 metre penetrasyon derinliği seçilmiştir.

Profilde elde edilen radargram kesitlerinde yoğun kırık formları tespit edilmiştir. Yaklaşık olarak 3.50-4.00 metre derinlikte ve 60.00 ile 240.00 traces aralığında kırıklı anomali yapısı olduğu, yapılan hız analizleri ile doğrulanmıştır (Şekil 28, Şekil 29).
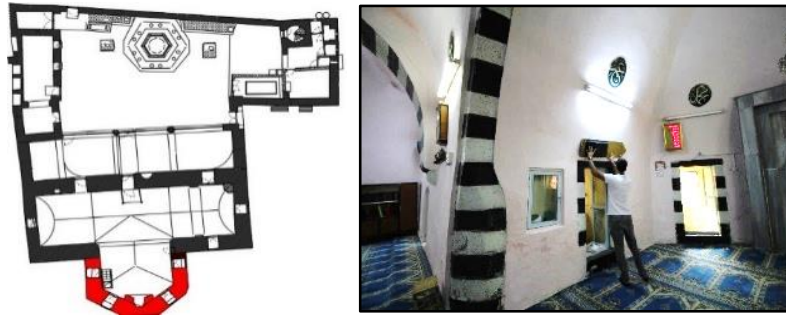

Şekil 28.Hoca Ahmet (Ayn Minare) Cami aks kayması bulunan harim güney duvarında yapılan GPR 3 taramaları ve konumları

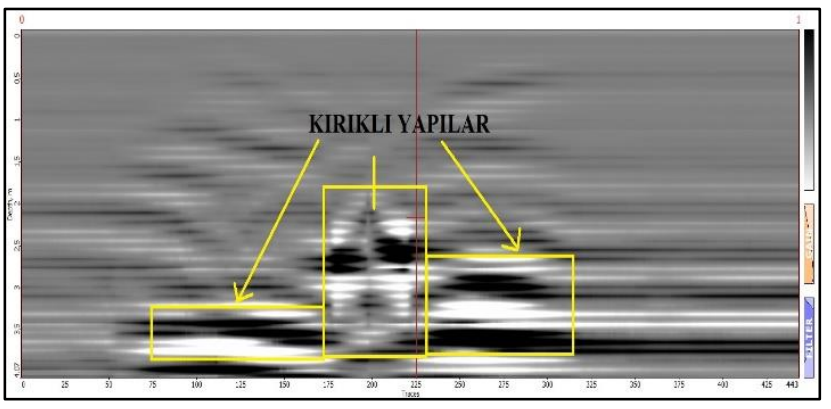

Şekil 29. Hoca Ahmet (Ayn Minare) Cami aks kayması bulunan harim güney duvarında yapılan GPR 3 taramalar sonucu elde edilen radargram kesitleri

\section{Georadar (GPR) 4 duvar taramalart ve konumlart}

Cami harim bölümünün güneybatı duvarında yapılan georadar (GPR) taramalarında, 14.00 metre profil boyu ve 4.00 metre penetrasyon derinliğgi seçilmiştir. Profilde elde edilen radargram kesitlerinde duvarda kırik deformasyonları olduğu tespit edilmiştir. Yaklaşık olarak 1.50- 2.00 metre derinlikte ve 60.00 ile 180 traces aralığında kırıklı ve çatlaklı anomali yapılarını olduğu yapılan hız analizleri ile doğrulanmıştır (Şekil 30, Şekil 31).
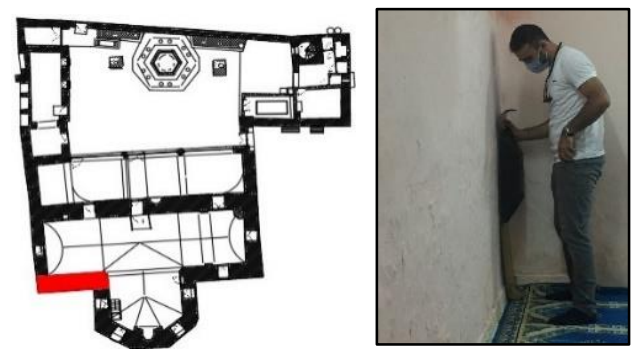

Şekil 30. Hoca Ahmet (Ayn Minare) Cami aks kayması bulunan harim güneybatı duvarında yapılan GPR 4 taramaları ve konumları

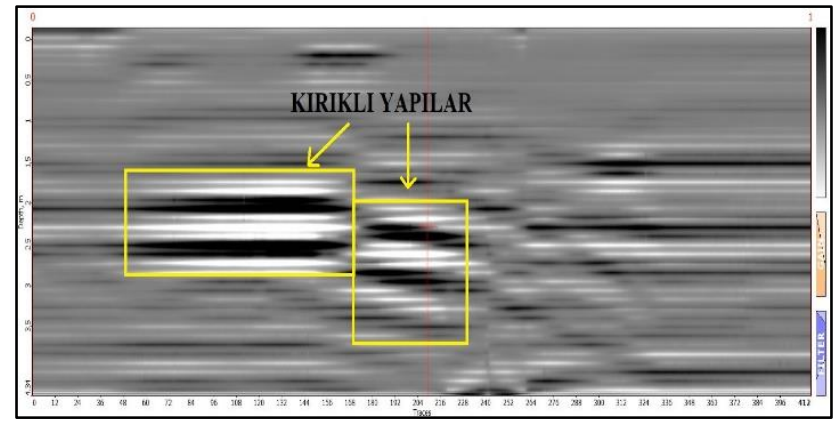

Şekil 31. Hoca Ahmet (Ayn Minare) Cami aks kayması bulunan harim güneybatı duvarında yapılan GPR 4 taramaları sonucu elde edilen radargram kesitleri

\section{Georadar (GPR) 5 duvar taramalart ve konumlart}

Harim girişinin yer aldığ 1 kuzey duvarında yapılan georadar (GPR) taramalarında 15 metre profil boyu 4 metre penetrasyon derinliği seçilmiştir.

Profilde elde edilen radargram kesitlerinde, duvar yüzeyinde yaklaşık 2.50-4.00 metre derinlikte ve 150.00-300.00 traces aralığında kırıklı ve çatlaklı anomali yapılarının olduğu yapılan hız analizleri ile doğrulanmıştır (Şekil 32, Şekil 33).
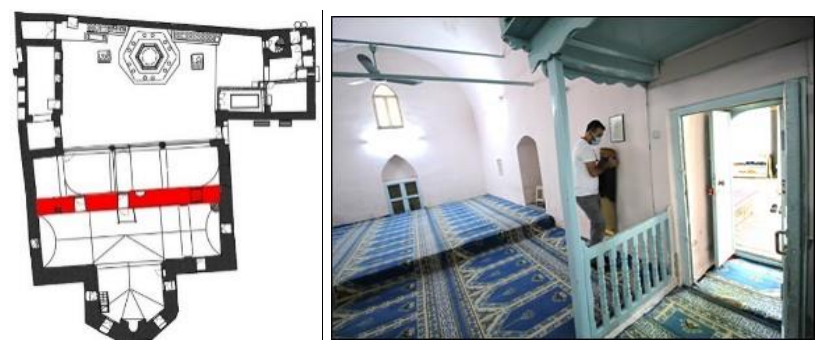

Şekil 32. Hoca Ahmet (Ayn Minare) Cami aks kayması bulunan harim kuzey duvarında yapılan GPR 5 taramaları ve konumları 


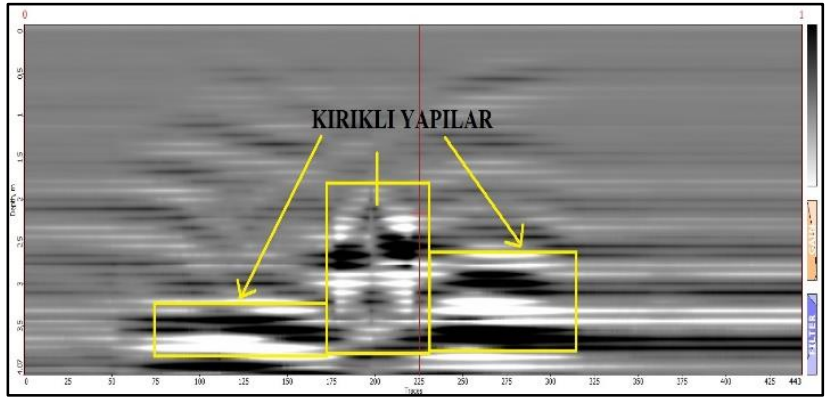

Şekil 33. Hoca Ahmet (Ayn Minare) Cami aks kayması bulunan harim kuzey duvarında yapılan GPR 5 taramaları sonucu elde edilen radargram kesitleri

\section{Sonuç ve Öneriler}

Hoca Ahmet (Ayn Minare) camide meydana gelen yapısal sorunların görsel analizlerle tespiti sonras1 tahribatsız yöntemlerden biri olan georadar (GPR) taramaları ile aletsel ölçümler yapılmıştır.

Alan çalışmasının yapıldığı bu çalışmada, Georadar (GPR) taramaları ile caminin zemininde çökme, duvarlarında çatlak ve kırıkların yerleri ve boyutları belirlenmiştir.

Camide yapılan alan çalışmasında görsel olarak tespit edilen hasarların zemin yapısına bağlı oluştuğu bu çalışma ile netleştirilmiştir.

Caminin zemin ve duvarlarındaki hasar ve düzeylerinin georadar (GPR) taramalarıla tespit edilmesi, çalışmanın hedefine ulaşmasını sağlamıştır.

Hoca Ahmet (Ayn Minare) Camide yapilan georadar (GPR) taramalarında, zemin için penetrasyon derinliği 20 metre, duvarlarda 4,00 metre alınmıştır. Taramalar sonucu elde edilen radargram kesitlerinde zeminde boşluk, su tablası, çökme, duvarlarda ise çatlak ve kırık olduğu belirlenerek, tüm deformasyonlar radargram kesitlerinde işaretlenmiştir.

Hoca Ahmet (Ayn Minare) camide tahribatsız yöntemlerden biri olan georadar (GPR) taramaları ile cami zemini ve duvarlarındaki hasar konumları ve düzeyleri belirlenmiştir.
Hoca Ahmet Cami avlusunda yapilan taramalarda, zeminde GPR 9 bölgesinde, yaklaşı olarak 12,50 metre derinlikte, 20,00 metre uzunluğunda bir adet su tablası olduğu ve su tablasının kısmi çökmelere yol açtığı görülmüştür. Tespit edilen bu yapının su kanalı ya da kanalizasyon şebekesine ait olduğu düşünülmektedir.

Camide ana malzeme olarak kullanılan bazalt taş malzemenin kullanıldığı duvarlarda, mevcut gaz boşluklarına bağlı çatlak, kırık deformasyonları oluştuğu tespit edilmiştir.

Caminin Ilgaz sokakta güneydoğu duvarında yapılan georadar (GPR)10 taramalarında 2,00 metre derinlikte ve 2,00 metre çapında bir adet boşluk anomalisi tespit edilmiştir. Taramalar sonucunda tespit edilen anomali nedeniyle caminin harim duvarının bulunduğu zeminde, zaman içinde suyun etkisiyle çökmeler, duvarlardaki aks kaymasının oluştuğu görülmüştür.

Caminin özel vakıf mülkiyetinde olması nedeniyle kapsaml onarim veya restorasyonlarının yapılmaması, mevcut hasarların zaman içinde artmasına neden olmuştur. Bu nedenle Hoca Ahmet (Ayn Minare) cami ve benzeri yapiların mevcut hasarlarının ivedilikle giderilmesi için özel vakıf mülkiyetinden alınarak, kamulaştırılması sağlanmalıdır.

Caminin kapsaml1 rölöve, restorasyon ve restitüsyon ile bilimsel ve akademik etkinliği olan uzmanlar tarafından önerilen güçlendirme uygulamalarını içeren projeler hazırlanmalıdır.

Camideki hasarların tahribatsız yöntemlerle tespitinin yanında uzmanlar tarafindan belirlenen bölgelerde gözlem çukurları açılarak, zeminin fiziksel durumu tespit edilmelidir.

Zemin iyileştirme yöntemlerinin camide uygulanması ve aks kayması olan ve gerekli tüm duvarlar askiya alınarak, mevcut hasarlara yönelik güçlendirme uygulamaları yapılmalıdır. 
$\mathrm{Bu}$ çalışma ile tarihi yapılardaki hasarların tespitinde tahribatsiz yöntemlerin uygulanabilirliği ve güvenilirliği doğrulanmıştır. $\mathrm{Bu}$ nedenle tarihi yapılardaki hasarların tespiti aşamasında bu tür tahribatsız yöntemlerle araştırılması ve yaygınlaştırılması bu yapıların yaşatılması ile sürdürülebilirliğini arttıracaktır.

Yapılan alan çalışması sonrasında, Hoca Ahmet (Ayn Minare) Cami mevcut hasarları görsel ve aletsel olarak tespit edilmiș, cami için rehber niteliğindeki öneriler sunularak çalışma tamamlanmıştır.

\section{Teşekkür}

$\mathrm{Bu}$ çalışma, 2019 yılında Dicle Üniversitesi Bilimsel Araştırma Projesi Koordinatörlügü tarafından desteklenmiş olan Mimarlık 19.008 no'lu "Diyarbakır Tarihi İskender Paşa ve Hoca Ahmet (Ayn Minare) Camilerinde Zemine Bağlı Oluşan Taşıyıcı Sistem Sorunlarının Georadar Yöntemi ile Tespit Edilmesi" başlıklı araştırma projesi kapsamında üretilmiştir. Desteklerinden dolayı DÜBAP Koordinatörlüğüne teşekkür ederiz.

\section{Kaynaklar}

[1] B.B. Demirci, "Yer Radarı (GPR) Jeofizik Yöntemi ve Kullanıldığı Alanlar" MTA Doğal Kaynaklar ve Ekonomi Bülteni (14) pp.56. 2012.

[2] C. Tareco, H. Grangeia, M. Varum, M. Senos. A high resolution GPR experiment to characterize the internal structure of a damaged adobe wall. First Break, 27(8):7984. 2009

[3] Diyarbakır Büyükşehir Belediyesi KAİP Planı Uygulama Hükümleri Raporu 2012.
[4] O. C. Tuncer, "Diyarbakır Camileri" Diyarbakır Büyükşsehir Belediyesi Yayınları Diyarbakır.pp.145. 1996

[5] İ. Yılmazçelik, "XIX. Yüzyılın ilk yarısında Diyarbakır (1790-1840)”, Türk Tarih Kurumu Yayınları, Ankara. s:58. 1995.

[6] E. Akmaz, Bilgiç. "Diyarbakır Hoca Ahmed (Ayni Minare) Camii restorasyon önerisi" Dicle Üniversitesi Fen Bilimleri Enstitüsü, Yayımlanmamış Yüksek Lisans Tezi. Diyarbakır. 2019.

[7] K.J., Sandmeier, "Reflexw 4.2 Manuel Book". Sandmeier Software, Zipser Strabe 1, D-76227 Karlsruhe, Germany, 2003

[8] E. Candansayar. "Yer Radarı (Ground Penetrating Radar - GPR)" JFM409 Elektromanyetik yöntemler ders notu. Ankara Üniversitesi, Mühendislik Fakültesi, Jeofizik Mühendisliği Bölümü. Ankara.2019.

[9] A. Anaran, Hoca Ahmet (Ayn) Minare cami zemin duvar bazlı yayımlanmamış jeofizik etüt raporu.2020.

\section{Internet Kaynakları}

URL1.

https://commons. wikimedia.org/w/index.php?curid=781 $\underline{8230}$ (Erişim Tarihi:24.05.2021)

URL2.

https://tr.wikipedia.org/wiki/Dosya:Diyarbakir in Turke y.svg (Erişim Tarihi:20.05.2021)

URL3.

Phthon-3 GPR. (Erişim Tarihi:21.05.2021). RadarSystemsInc.Products.http://www.radsys.lv/en/prod ucts-soft/products/prod/6

URL4

http://www.radsys.lv/en/index) (Erişim Tarihi: 25.05.2021)

URL5.

https://www.netinbag.com/tr/science/what-ispenetration-depth.htm (Erişim Tarihi: 18.05.2021)

URL 6 https://tr.wikipedia.org/wiki/ yeraltı suyu seviyesi (Erişim Tarihi:25.05.2021). 